\title{
A HISTOCHEMICAL STUDY ON THE GLYCOGEN SYNTHESIZING ENZYME IN THE MYOMETRIUM OF THE PREGNANT AND PSEUDOPREGNANT RAT
}

\author{
WALTER J. BO AND MAVIS S. SMITH \\ Department of Anatomy, Bowman Gray School of Medicine, \\ Winston-Salem, North Carolina, U.S.A.
}

(Received 2nd Fuly 1965, revised 8th December 1965)

Summary. Glycogen and the activity of phosphorylase and glycogen synthetase were determined histochemically in the myometrium of the pseudopregnant (with and without deciduomata) and pregnant rat. In the pseudopregnant rat without deciduomata the activity of the two enzymes and the amount of glycogen present in the myometrium were greatest in the animals autopsied on the 11th to the 14th day. Phosphorylase activity was strong in both muscle layers while glycogen synthetase activity was present only in the outer longitudinal muscle layer. More glycogen granules were observed in the outer longitudinal than in the inner circular muscle layer. In the uteri with deciduomata the concentration of glycogen and the activity of phosphorylase and glycogen synthetase in the uterine muscle were highest in the rats killed on the 12th and 13th day of pseudopregnancy. The increase was noted primarily in the outer longitudinal muscle layer. The increase in phosphorylase activity was only slight in comparison with glycogen synthetase activity and there was no great reduction in phosphorylase activity after the 13th day as was observed for glycogen synthetase activity. An increase in the activity of the two enzymes and the amount of the polysaccharide was noted in the myometrium of rats autopsied on the 18th day of gestation which continued to the 21 st day. A marked drop in the glycogen and glycogen synthetase activity of the myometrium was observed in the post-partum ( 1 to 5 days) rats while phosphorylase activity decreased slightly in the inner circular muscle layer.

The in-vitro studies show that glycogen synthesized from glucose-1phosphate and uridine diphosphate glucose can be observed in the myometrium of the pseudopregnant (with and without deciduomata) and pregnant rat. The glycogen content of the myometrium correlated more with glycogen synthetase activity than with phosphorylase activity.

It is questionable whether the increase in glycogen and the activity of phosphorylase and glycogen synthetase can be explained by the action of oestrogen and progesterone. The possibility of relaxin playing a role in increasing enzymatic activity and the amount of glycogen in the myometrium is discussed. 


\section{INTRODUCTION}

The concentration of glycogen in the rat uterus is highest following oestrogen stimulation (Boettinger, 1946). Bo \& Atkinson (1952) demonstrated that the polysaccharide is localized primarily in the longitudinal layer and is irregularly distributed in the circular layer of the rat myometrium. Biochemical and histochemical studies have shown that, in the rat, phosphorylase activity is highest following oestrogen stimulation and is localized primarily in the myometrium (Leonard, 1958; Bo, 1959). Glycogen synthetase activity has been detected in the longitudinal muscle of the rat uterus, but is not consistently observed in all uterine sections as is phosphorylase (Bo \& Smith, 1964).

Glycogen synthetase and phosphorylase synthesize 1,4 linkages of glycogenlike polysaccharides with uridine diphosphate glucose (UDPG) or glucose-1phosphate (G-1-P) as their respective substrate. Unlike UDPG-glycogen synthetase, the action of phosphorylase is readily reversible so that it may be involved in synthesis and breakdown of the glycogen. However, there seems to be conclusive evidence that glycogen is synthesized from UDPG by the action of UDPG-glycogen synthetase with the branching enzyme (amylo-1,4-1,6-transglucosidase) while phosphorylase along with a debranching enzyme (amylo1,6-glucosidase) is concerned with the breakdown of the polysaccharide to G-1-P (Stetten \& Stetten, 1960).

Although the glycogen content of the rat myometrium during gestation has received some attention (Kostyo, 1957; Kroc, Steinetz \& Beach, 1959; Connolly, Bitman, Cecil \& Wrenn, 1962; Padykula \& Richardson, 1963), the activity of the glycogen synthesizing enzyme in the uterus at different times of gestation has not been considered. In order to help understand the problem of glycogen concentration in the uterus during gestation, the following experiment was designed to study glycogen and the activity of phosphorylase and glycogen synthetase in the myometrium of the pregnant and pseudopregnant rat (with and without deciduomata) and following parturition.

\section{MATERIALS AND METHODS}

One hundred and thirty-five female rats (Dublin Farms) were used in this study. Twenty-nine animals were made pseudopregnant by stimulating the cervix with a glass rod on the morning of oestrus, and the lst day of pseudopregnancy was considered to be the time when $50 \%$ or more of the cells in the vaginal smear were leucocytes. Rats were autopsied every day from the 4th to the 14th day of pseudopregnancy. Forty-one rats were made pseudopregnant as described above. On the 4th day of pseudopregnancy one uterine horn was traumatized with a thread to produce the deciduoma and animals were autopsied every day from the 5th to the 19th day of pseudopregnancy. In all the pseudopregnant rats vaginal smears were examined daily. Fifty-nine rats were mated and the presence of spermatozoa in the vaginal smear was considered Day 0 of gestation. Animals were autopsied daily from the 5 th to the 22 nd day of pregnancy. Six animals were killed from the 1 st to the 5 th day following parturition.

The rats were killed with ether vapours and at autopsy a portion of the uterus 
was quenched in iso-pentane cooled with liquid nitrogen. In the latter stages of pregnancy the placental disk was removed before quenching the uterus. Frozen sections were made on the cryostat at $16 \mu$ and adjacent sections were treated for the identification of glycogen, phosphorylase activity, glycogen synthetase activity, and for general orientation sections were stained with haematoxylin and eosin.

To demonstrate phosphorylase activity the technique of Takeuchi \& Kuriaki (1955) was employed, and the procedure of Takeuchi \& Glenner (1961) was followed for the demonstration of UDPG-glycogen synthetase. For the identification of glycogen the frozen sections were fixed in cold PAF $(10 \%$ formalin and $80 \%$ ethyl alcohol, saturated with picric acid). The sections were then treated with periodic acid and stained with leucofuchsin following the procedure of McManus (1948).

\section{RESULTS}

It can be seen from Table 1 that in the pseudopregnant rats without deciduomata phosphorylase activity, glycogen synthetase activity and the amount of

TABLE 1

PHOSPHORYLASE, GLYOGEN SYNTHETASE, AND GLYCOGEN IN THE MYOMETRIUM OF THE PREGNANT AND PSEUDOPREGNANT RAT

\begin{tabular}{l|c|c|c|c|c|c|c|c}
\hline \multirow{2}{*}{$\begin{array}{c}\text { Condition of } \\
\text { animals }\end{array}$} & Days & $\begin{array}{c}\text { No. of } \\
\text { animals }\end{array}$ & \multicolumn{2}{c|}{$\begin{array}{c}\text { Phosphorylase } \\
\begin{array}{c}\text { Outer } \\
\text { longitudinal }\end{array}\end{array}$} & $\begin{array}{c}\text { Inner } \\
\text { circular }\end{array}$ & $\begin{array}{c}\text { Glycogen synthetase } \\
\text { Outer }\end{array}$ & \multicolumn{2}{c}{ Glycogen } \\
\hline longitudinal & $\begin{array}{c}\text { Inner } \\
\text { circular }\end{array}$ & $\begin{array}{c}\text { Outer } \\
\text { longitudinal }\end{array}$ & $\begin{array}{c}\text { Inner } \\
\text { circular }\end{array}$ \\
\hline Pseudopregnant* & $4-10$ & 18 & ++ & + & \pm & - & \pm & \pm \\
Pseudopregnant* & $11-14$ & 11 & +++ & +++ & + & - & +++ & + \\
with & $5-11$ & 24 & ++ & + & \pm & - & + & \pm \\
deciduomata & $12-13$ & 6 & +++ & ++ & +++ & + & +++ & + \\
Pregnant $\dagger$ & $14-19$ & 11 & ++ & ++ & \pm & - & + & \pm \\
& $5-12$ & 30 & ++ & + & \pm & - & \pm & \pm \\
Post-partum & $13-17$ & 16 & ++ & ++ & + & \pm & + & \pm \\
& $18-21$ & 13 & +++++ & ++++ & +++ & ++ & ++++ & +++ \\
& $1-5$ & 6 & +++++ & +++ & \pm & \pm & \pm & \pm \\
\hline
\end{tabular}

* Day 1 of pseudopregnancy was the 1 st day on which $50 \%$ or more leucocytes were present in the vaginal smear following cervical stimulation.

$\dagger$ The day spermatozoa were noted in the vaginal smear was considered as Day '0' of gestation.

+ to $t+t++$, Increasing intensities of staining reaction; - , no staining; \pm doubtful reaction.

glycogen in the myometrium were greatest in the rats autopsied from the 11 th to the 14th day (Pl. 1, Figs. 1, 3 and 5). Phosphorylase activity was strong in both muscle layers while glycogen synthetase activity was present only in the outer longitudinal muscle layer. More glycogen granules were noted in the outer longitudinal than in the inner circular muscle layer.

In the pseudopregnant rats with deciduomata the activity of phosphorylase and glycogen synthetase and the amount of glycogen were greater in the animals autopsied on the 12th and 13th day than in animals before or after the above dates (Pl. 1, Figs. 2, 4 and 6). The increase was noted primarily in the outer longitudinal muscle layer. However, the increase in phosphorylase activity was 
only slight in comparison with glycogen synthetase activity and there was no great reduction in phosphorylase activity after the 13th day as was noted for glycogen synthetase activity.

An increase in phosphorylase activity, glycogen synthetase activity and the amount of glycogen was observed in the myometrium of rats autopsied from the 18 to 21 days of gestation (Pl. 2, Figs. 7, 9 and 11). Enzymatic activities and the amount of glycogen were greater in the outer longitudinal muscle layer than in the inner circular muscle layer.

In the post-partum animals ( 1 to 5 days) a great reduction in glycogen synthetase activity and the amount of glycogen in both layers of the myometrium was observed (Pl. 2, Figs. 10 and 12). Phosphorylase activity was only slightly reduced in the inner circular muscle layer of the post-partum rats (Pl. 2, Fig. 8).

\section{DISCUSSION}

The in-vitro studies show that glycogen synthesized from UDPG and G-1-P can be observed in the myometrium of the pregnant and pseudopregnant (with and without deciduomata) rat. The results show that the glycogen and the activity of phosphorylase and glycogen synthetase of the rat myometrium vary during pseudopregnancy (with or without deciduomata) and pregnancy. However, the degree of variation in phosphorylase activity of the pregnant and pseudopregnant rats (with or without deciduomata) was not as great as glycogen synthetase activity. The amount of glycogen varied more with the activity of glycogen synthetase than with phosphorylase activity. The results seem to indicate that the polysaccharide is synthesized from UDPG through the action of glycogen synthetase.

The vaginal smears of all the pseudopregnant rats contained leucocytes with a few nucleated cells until they were killed. However, the rats that were autopsied from the 11 th to the 14th day of pseudopregnancy (without deciduomata) had large hyperaemic uteri, and it was in these animals that the greatest amount of glycogen granules was noted as well as the greatest activity for phosphorylase and glycogen synthetase. According to Everett (1961) the termination of pseudopregnancy is the onset of the next oestrus but the change is not abrupt since mucified cells are present in the vaginal smear. In our animals no sign of the first oestrus before autopsy was observed. The rats that showed the greatest amount of the polysaccharide and activity of the two enzymes may have been at the terminal part of pseudopregnancy which may help to explain the results obtained.

In the pseudopregnant rats with deciduomata, the concentrations of glycogen and the activity of phosphorylase and glycogen synthetase were greatest in the animals autopsied on the 12th and 13th day of pseudopregnancy. This increase coincides with the greatest development of the decidua and the metrial gland (Velardo, Dawson, Olsen \& Hisaw, 1953). In the pregnant rats, the marked increase in the amount of glycogen, phosphorylase activity and glycogen synthetase activity was noted on the 18th day of gestation and extended to the 21 st day, indicating that glycogen is necessary as a source of energy for parturition. The marked increase in the amount of glycogen granules and the activity 
of the enzymes in the myometrium of the pseudopregnant (with and without deciduomata) and pregnant rats is greater than that observed in ovariectomized rats treated with ovarian hormones (Bo \& Atkinson, 1952; Bo, 1959; Bo \& Smith, 1964). It is questionable whether such an increase in glycogen concentration, phosphorylase activity and glycogen synthetase activity at the end of gestation and in the pseudopregnant rat can be attributed to the action of oestrogen or the combination of oestrogen and progesterone. It has been suggested that the metrial gland is partly concerned with the secretion of relaxin (Wislocki, Wiess, Burgos \& Ellis, 1957). The ovaries, placentae and uteri are other possible sources of relaxin (Zarrow, 1961). Schmidt \& Leonard (1960) reported that relaxin increased total phosphorylase activity of the uterus in the ovariectomized rat and the over-all effect on phosphorylase activity was similar to that of oestrogen. No information is available on the effect of relaxin on the glycogen synthetase activity of the rat uterus. Steinetz, Beach, Blye \& Kroc (1957) reported that a single injection of relaxin to oestrogen-primed castrate rats increased the glycogen concentration of the rat uterus. Whether the increase in phosphorylase activity, glycogen synthetase activity and the amount of glycogen observed in the present study is due partly to the action of relaxin has not been established.

\section{ACKNOWLEDGMENT}

This investigation was supported by Public Health Service Research Grant AMO8029, from the National Institute of Arthritis and Metabolic Diseases.

\section{REFERENCES}

Bo, W. J. (1959) Distribution of phosphorylase in the uteri of cyclic and hormone treated rats. $\mathcal{J}$. Histochem. Cytochem. 7, 403.

Bo, W. J. \& Atkinson, W. B. (1952) Histochemical studies on glycogen deposition in the uterus of the rat. I. In intact cyclic animals and in castrates treated with ovarian hormones. Anat. Rec. 113, 91.

Bo, W. J. \& Sмгтн, M. S. (1964) Further histochemical observations on uridine diphosphate glucoseglycogen transferase activity of the uterus. F. Histochem. Cytochem. 12, 393.

Boettinger, E. G. (1946) Changes in the glycogen and water content of the rat uterus. F. cell. comp. Physiol. 27, 9.

Connolly, M. R., Brtman, J., Cecrl, H. G. \& Wrenn, R. (1962) Water, electrolyte, glycogen and histamine content of the rat uterus during pregnancy. Am. F. Physiol. 203, 717.

EveretT, J. W. (1961) The mammalian female reproductive cycle and its controlling mechanisms. Sex and Internal Secretions, 4th edn, p. 497. Ed. W. C. Young. Williams \& Wilkins, Baltimore.

Kostyo, J. L. (1957) A study of the glycogen levels of the rat uterus and certain skeletal muscles during pregnancy. Endocrinology, 60, 33.

Kroc, R. L., Steinetz, B. G. \& BEACH, V. L. (1959) The effects of estrogens, progestogens, and relaxin in pregnant and non-pregnant laboratory rodents. Ann. N. X. Acad. Sci. 75, 942.

LEONARD, S. L. (1958) Hormonal effects on phosphorylase activity in the rat uterus. Endocrinology, $63,853$.

McManus, J. F. A. (1948) The periodic acid routine applied to the kidney. Am. F. Path. 24, 643.

Padykula, H. \& Richardson, D. (1963) A correlated histochemical and biochemical study of glycogen storage in the rat placenta. Am. $\mathcal{F}$. Anat. 112, 215.

Schmidt, J. E. \& Leonard, S. L. (1960) The effect of relaxin on uterine phosphorylase in the rat. Endocrinology, 67, 663.

Stetten, D. \& Stetten, M. R. (1960) Glycogen metabolism. Physiol. Rev. 40, 505.

Steinetz, B. G., Beach, V. L., Blye, R. P. \& Kroc, R. L. (1957) Changes in the composition of the rat uterus following a single injection of relaxin. Endocrinology, 61, 287. 
TAkeuchi, T. \& Glenner, G. (1961) Histochemical demonstration of the uridine diphosphate glucoseglycogen transferase in animal tissues. 7 . Histochem. Cytochem. 9, 304.

TAKEUCHI, T. \& KURIAKI, H. (1955) Histochemical detection of phosphorylase in animal tissues. $\mathcal{F}$. Histochem. Cytochem. 3, 153.

Velardo, J. T., Dawson, A. B., Olsen, A. G. \& Hisaw, F. L. (1953) Sequence of histological changes in the uterus and vagina of the rat during prolongation of pseudopregnancy associated with presence of deciduomata. Am. F. Anat. 93, 273.

Wislocki, G. B., Wiess, L. P., Burgos, M. H. \& Elurs, R. A. (1957) The cytology, histochemistry and electron microscopy of the granular cells of the metrial gland of the gravid rat. F. Anat. 91, 130.

Zarrow, M. X. (1961) Gestation. Sex and Internal Secretions, 4th edn, p. 958. Ed. W. G. Young. Williams \& Wilkins, Baltimore.

\section{EXPLANATION OF PLATES}

\section{PLATE 1}

Fig. 1. Photomicrograph of a transverse section of the uterus demonstrating phosphorylase activity. Enzymatic activity is strong in the outer longitudinal and inner circular muscle layers and is also present in the luminal epithelium. The animal was autopsied on the 11 th day of pseudopregnancy without a deciduomata. $\times 100$.

FIG. 2. Photomicrograph of a transverse section of the uterus demonstrating phosphorylase activity. The activity of the enzyme is stronger in the outer longitudinal than in the inner circular muscle layer. The animal was autopsied on the 13th day of pseudopregnancy with a deciduomata. $\times 90$.

FIG. 3. Photomicrograph of a uterine section treated to demonstrate glycogen synthetase activity. The transverse section shows very slight enzymatic activity only in the outer longitudinal muscle layer. The rat was autopsied on the 11 th day of pseudopregnancy without deciduomata. $\times 125$.

Fic. 4. Photomicrograph of a uterine section treated to demonstrate glycogen synthetase activity. The transverse section shows a good response in the outer longitudinal muscle layer. The animal was autopsied on the 13th day of pseudopregnancy with a deciduomata. $\times 165$.

Frg. 5. Photomicrograph of a transverse section of the uterus stained to demonstrate glycogen. The glycogen granules are present in great numbers in the outer longitudinal muscle layer and can also be seen in the walls of the blood vessels. The rat was autopsied on the 11 th day of pseudopregnancy without a deciduomata. $\times 140$.

Frg. 6. Photomicrograph of a transverse section of the uterus stained to demonstrate glycogen. The glycogen granules are present in great numbers in the outer longitudinal muscle layer. In the inner circular muscle layer, glycogen granules are scattered throughout the cells. The animal was autopsied on the 13th day of pseudopregnancy with deciduomata. $\times 70$.

\section{PLATE 2}

FIG. 7. Photomicrograph of a transverse section of the uterus demonstrating phosphorylase activity. The activity is strong in both the outer longitudinal and the inner circular muscle layers. The animal was autopsied on the 21 st day of gestation. $\times 100$.

FIG. 8. Photomicrograph of a transverse section of the uterus demonstrating phosphorylase activity. Enzymatic activity is not as strong in the inner circular layer as in the outer longitudinal muscle layer. The rat was autopsied on the lst day following parturition. $x$ 90.

Fig. 9. Photomicrograph of a uterine section treated to demonstrate glycogen synthetase activity. The transverse section shows a good enzymatic reaction in the outer longitudinal muscle layer and a weaker enzymatic reaction in the inner circular muscle layer. The animal was autopsied on the 21 st day of gestation. $\times 110$.

FIG. 10. Photomicrograph of a uterine section treated to demonstrate glycogen synthetase activity. The transverse section shows a very slight enzymatic activity in the outer longitudinal muscle layer. The animal was autopsied on the 1st day following parturition. $\times 75$.

Fig. 11. Photomicrograph of a transverse section of the uterus treated to demonstrate glycogen. In the outer longitudinal muscle layer the glycogen granules are in great numbers. The animal was autopsied on the 21 st day of gestation. $\times 50$.

FIG. 12. Photomicrograph of a uterine section treated to demonstrate glycogen. The transverse section shows almost a complete absence of glycogen granules in the outer and inner circular muscle layers of the myometrium. The animal was autopsied on the 1 st day following parturition. $\times 50$. 
PLATE 1

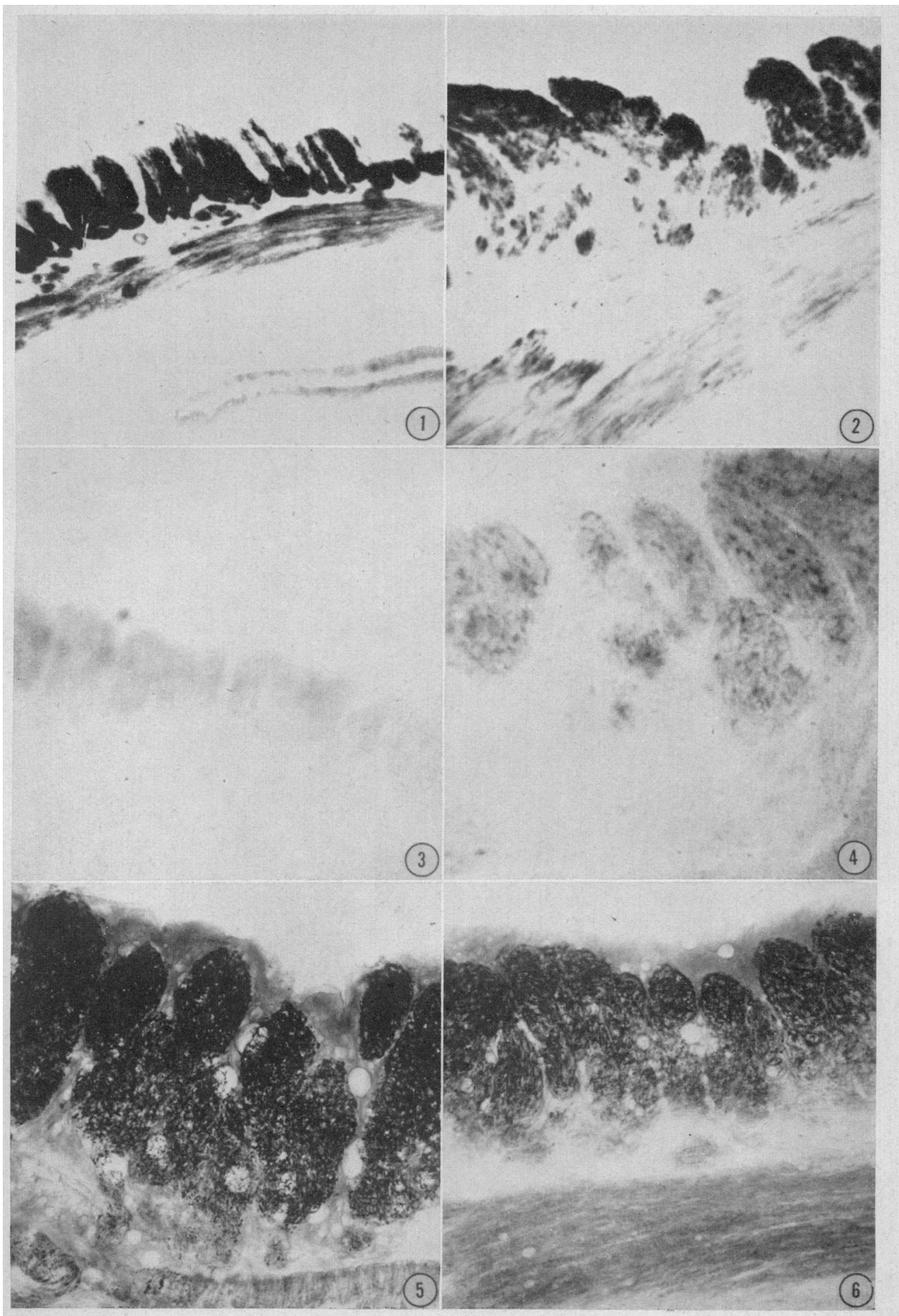

(Facing p. 242) 
PIATE 2

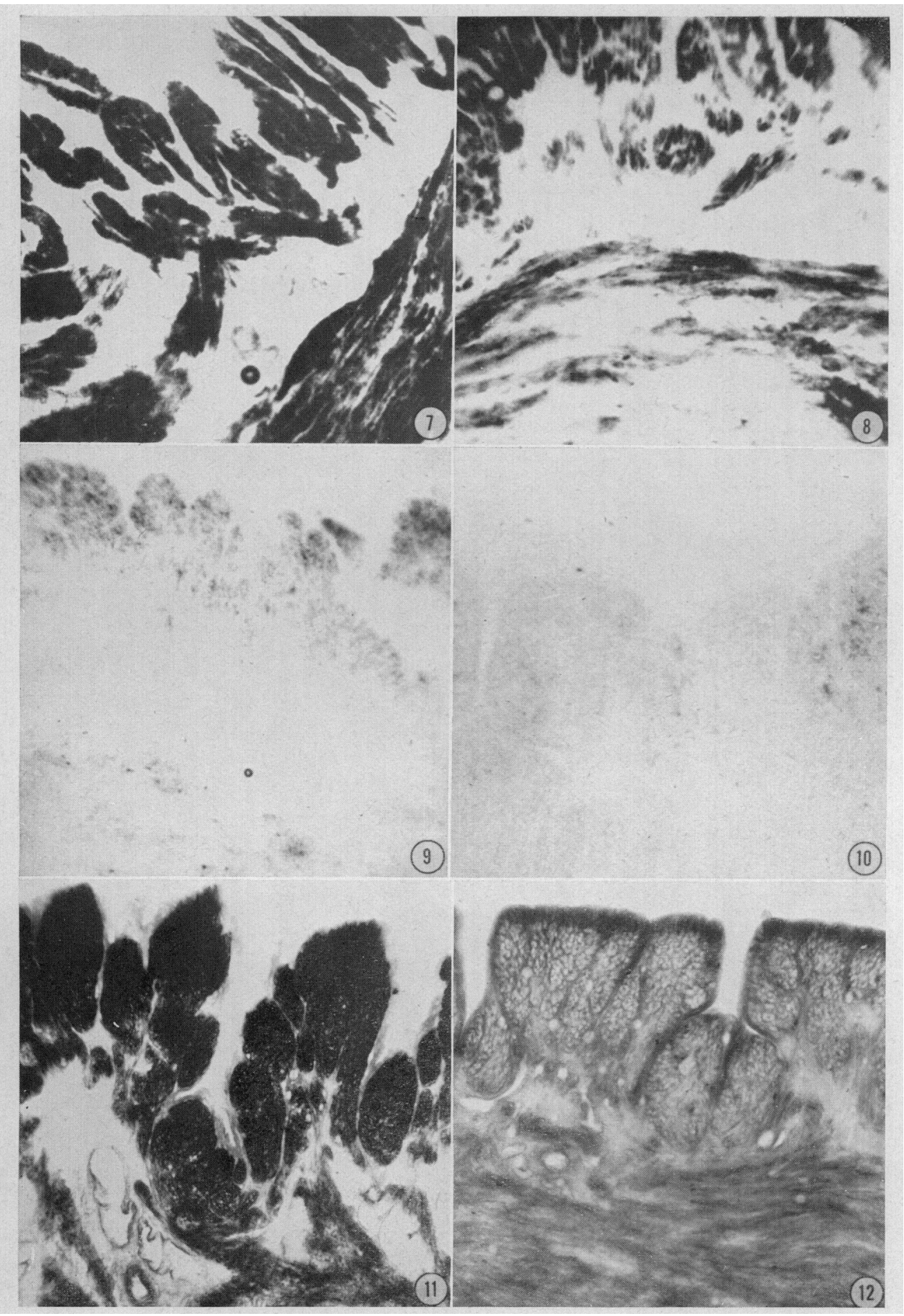

